\title{
Fareins - Zac de Montfray (zone E)
}

Fouille préventive (2013)

\section{Tony Silvino}

\section{(2) OpenEdition \\ Journals}

Édition électronique

URL : https://journals.openedition.org/adlfi/14409

ISSN : 2114-0502

Éditeur

Ministère de la Culture

Référence électronique

Tony Silvino, « Fareins - Zac de Montfray (zone E) » [notice archéologique], ADLFI. Archéologie de la France - Informations [En ligne], Auvergne-Rhône-Alpes, mis en ligne le 26 mars 2015, consulté le 23 juillet 2021. URL : http://journals.openedition.org/adlfi/14409

Ce document a été généré automatiquement le 23 juillet 2021.

(c) ministère de la Culture et de la Communication, CNRS 


\title{
Fareins - Zac de Montfray (zone E)
}

\author{
Fouille préventive (2013)
}

\section{Tony Silvino}

\section{NOTE DE L'ÉDITEUR}

Organisme porteur de l'opération : Éveha

1 L'aménagement du Parc d'activités de Montfray a engendré une fouille d'archéologie préventive sur une parcelle localisée à l'extrême est de l'emprise du projet (zone E). L'opération a concerné une surface de $4200 \mathrm{~m}^{2}$. La fouille a mis en évidence deux occupations antiques successives, ainsi qu'un ensemble de structures marginales attribué à une période plus récente.

2 La première occupation comprend un probable enclos fossoyé à l'intérieur duquel ont été aménagés une série de foyers excavés à plan rectangulaire, ainsi qu'un ensemble de fosses. Si les structures de combustion, orientées est-ouest, sont relativement bien conservées, leur destination exacte s'avère indéterminée. En effet, l'absence d'éléments probants dans leur comblement et à leur périphérie ne permet pas de plaider en faveur d'une fonction précise. Il convient de signaler que ce type de structure abonde sur les sites ruraux régionaux, mais les interprétations restent parfois hasardeuses et risquées. L'étude du mobilier céramique, associée aux résultats des analyses radiocarbone effectuées sur les charbons de bois des foyers, placent cette occupation au cours du $\mathrm{II}^{\mathrm{e}} \mathrm{s}$. apr. J.-C. Cette première fréquentation du site, au demeurant très lacunaire, témoigne tout de même d'une exploitation ou d'une mise en valeur du terrain. Elle est contemporaine de la zone funéraire située à $300 \mathrm{~m}$ plus à l'ouest.

3 Une restructuration de la parcelle est ensuite attestée, au plus tard au milieu du $\mathrm{III}^{\mathrm{e}} \mathrm{s}$. Elle se résume à l'aménagement de deux mares-abreuvoirs pour le bétail ainsi qu'une série de structures d'assainissement (puisards, fossés, etc.). Un petit enclos est également visible en limite de la parcelle. Cette installation, très certainement à fonction agro-pastorale, est desservie par un chemin dont seuls les fossés bordiers nous sont parvenus. L'ensemble de ces aménagements a livré des lots importants de 
mobiliers, mêlant aussi bien des éléments de la vie quotidienne (céramiques, amphores, verre, monnaie, etc.) que des éléments de construction (tuiles, galets et moellons) accréditant l'existence d'un établissement à proximité immédiate. Il faut également signaler, pour l'anecdote, la présence d'objets datables de l'âge du Bronze en position résiduelle.

4 Si les vestiges découverts à l'occasion de cette opération demeurent très fugaces, ils permettent tout de même de témoigner de la mise en valeur agro-pastorale en bordure d'un établissement rural du Haut-Empire.

\section{INDEX}

Année de l'opération : 2013

chronologie https://ark.frantiq.fr/ark:/26678/pcrtxT02uJOogm, https://ark.frantiq.fr/ark:/ 26678/pcrtof7EHNsS2e, https://ark.frantiq.fr/ark:/26678/pcrtZTmusVUU24, https:// ark.frantiq.fr/ark:/26678/pcrtIkSWVMVuqB, https://ark.frantiq.fr/ark:/26678/pcrtH5r3FYBpwe nature https://ark.frantiq.fr/ark:/26678/pcrtcJxzOpgs7T

lieux https://ark.frantiq.fr/ark:/26678/pcrtSEeAipsBlD, https://ark.frantiq.fr/ark:/26678/ crtB8WDyqd6u9, https://ark.frantiq.fr/ark:/26678/pcrtLWfwZwjwu2, https://ark.frantiq.fr/ ark:/26678/pcrt3EKtfLNZIg sujets https://ark.frantiq.fr/ark:/26678/pcrtKJVpuP3AET, https://ark.frantiq.fr/ark:/26678/ pcrtDlzbGxWvTo, https://ark.frantiq.fr/ark:/26678/pcrtbptj4SOA1W, https://ark.frantiq.fr/ark:/ 26678/pcrtVnWeKqGpcj, https://ark.frantiq.fr/ark:/26678/pcrtKei7jxhn32, https:// ark.frantiq.fr/ark:/26678/pcrtms2OAv82PY, https://ark.frantiq.fr/ark:/26678/pcrtJUwAaZ7Nz9

\section{AUTEURS}

\section{TONY SILVINO}

Éveha 